\title{
Molecular characterization and antibiotic resistance of Staphylococcus spp. isolated from cheese processing plants
}

\author{
Marjory Xavier Rodrigues, ${ }^{* 1}$ Nathália Cristina Cirone Silva, ${ }^{\dagger} \dagger$ Júlia Hellmeister Trevilin, ${ }^{*}$ \\ Melina Mary Bravo Cruzado,* Tsai Siu Mui,‡ Fábio Rodrigo Sanches Duarte,‡ Carmen J. Contreras Castillo,* \\ Solange Guidolin Canniatti-Brazaca, ${ }^{*}$ and Ernani Porto*2 \\ *Department of Agroindustry, Food and Nutrition, Luiz de Queiroz College of Agriculture, University of São Paulo, Piracicaba, São Paulo, \\ 13418-900, Brazil \\ †Department of Food Science, University of Campinas, Campinas, São Paulo, 13083-862, Brazil \\ $\ddagger$ Cell and Molecular Biology Laboratory, Center for Nuclear Energy in Agriculture, University of São Paulo, Piracicaba, São Paulo, \\ 13400-970, Brazil
}

\begin{abstract}
The aim of this research paper was to characterize coagulase-positive and coagulase-negative staphylococci from raw milk, Minas cheese, and production lines of Minas cheese processing. One hundred isolates from 3 different cheese producers were characterized using molecular approaches, such as PCR, molecular typing, and DNA sequencing. Staphylococcus aureus ( $88 \%$ of the isolates) was the most abundant followed by Staphylococcus epidermidis, Staphylococcus hyicus, and Staphylococcus warneri. Among the 22 enterotoxin genes tested, the most frequent was seh $(62 \%$ of the isolates), followed by sel $x$ and ser. Hemolysin genes were widely distributed across isolates, and Panton-Valentine leukocidin and toxic shock syndrome toxin genes were also identified. Methicillin-resistant $S$. aureus were staphylococcal cassette chromosome mec III, IVa, IVd, and others nontypeable. In the phenotypic antibiotic resistance, multiresistant isolates were detected and resistance to penicillin was the most observed. Using spa typing, we identified several types and described a new one, t14969, isolated from cheese. These findings suggest that antibiotic resistance and potentially virulent strains from different sources can be found in the Brazilian dairy processing environment. Further research should be conducted with collaboration from regulatory agencies to develop programs of prevention of virulent and resistant strain dissemination in dairy products and the processing environment.
\end{abstract}

Key words: cheese, staphylococci, antibiotic resistance, virulence factor

\footnotetext{
Received December 17, 2016.

Accepted February 4, 2017.

${ }^{1}$ Corresponding author: marjoryxavier@usp.br

${ }^{2}$ Deceased.
}

\section{INTRODUCTION}

Staphylococcus spp. are known worldwide as a cause of human and animal infections, such as bacteremia, wound infections (Podkowik et al., 2013), and mastitis (Podkowik et al., 2013; Luini et al., 2015). The species Staphylococcus aureus is the main etiological agent of mastitis in dairy cows (Luini et al., 2015), a disease economically important to the dairy industry (Hayakawa et al., 2001; Shaheen et al., 2016). In addition, staphylococci from bovine milk, excluding $S$. aureus, also represent a heterogeneous group of microorganisms, namely CNS, that are commonly associated with bovine mastitis (Lange et al., 2015). In different studies, CNS has been highlighted in human (Jean-Baptiste et al., 2011) and animal infections (Lange et al., 2015), and also in food poisoning cases (Podkowik et al., 2013).

Food poisoning is widely related to $S$. aureus and is frequently detected in milk and dairy products (Carfora et al., 2015; Jamali et al., 2015; Xing et al., 2016). In Brazil, milk and dairy products are among the foods most involved in foodborne disease outbreaks and in these cases $S$. aureus is the third most identified pathogen according to the Ministry of Health (2016); these data corroborate the importance of studies with isolates in Brazil. Specifically in cheese production, André et al. (2008) and Arcuri et al. (2010) showed that the source of $S$. aureus contamination could be multifactorial, such as raw milk, processing environment, and handlers. In general, $S$. aureus is a major concern for the food processing industry due to its virulence factors (Xing et al., 2016) and ability to form biofilm (Langsrud, 2009). Strains can produce coagulase, hemolysins, exfoliative toxins, toxic shock syndrome toxin-1, protein A, staphylococcal enterotoxins, in addition to others (Hayakawa et al., 2001).

Moreover, the presence of strains resistant to antibiotics has been reported and its transmission via food is 
a concern for public health (Jamali et al., 2015). Resistance of Staphylococcus aureus isolated from raw milk and dairy products to tetracycline (TET), kanamycin, gentamicin (GEN), streptomycin, methicillin, and other antibiotics was reported by Jamali et al. (2015). Other studies have described the antibiotic resistance of Staphylococcus spp. isolated from milk (André et al., 2008; Rola et al., 2015). Additionally, S. aureus is a pathogen identified by the World Health Organization as an international concern due to its resistance to antibacterial drugs (WHO, 2014). Considering this, the aim of this study was to characterize coagulasepositive and negative staphylococci isolated from raw milk, Minas cheese (fresh cheese), and production lines of Minas cheese processing. Virulence factor genes, antibiotic resistance genes, and antibiogram testing 11 different antibiotics were all assessed for all isolates; molecular typing of $S$. aureus [spa and staphylococcal cassette chromosome mec (SCCmec) types] was also performed.

\section{MATERIALS AND METHODS}

\section{Origin of Isolates and Dairy Descriptions}

One hundred isolates from the bacterial collection of Hygiene and Dairy Laboratory, University of São Paulo, Brazil, were used in this study. In a previous study performed by the Hygiene and Dairy Laboratory's research group (Silva, 2013), staphylococci were isolated using standard methods (Downes and Ito, 2001) from samples collected from 3 different processing plants of traditional Brazilian fresh cheese called Minas Frescal cheese or Minas cheese. All processing plants were located in São Paulo State, Brazil. The isolates used were storage at $-20^{\circ} \mathrm{C}$ and their origins are shown in Table 1.

Dairy A produced approximately $600 \mathrm{~kg}(\mathrm{~kg})$ of cheese per week and the pasteurization used was HTST.
Dairy B processed $150 \mathrm{~kg}$ per week and slow pasteurization was used. Dairy $\mathrm{C}$ produced its own milk, the pasteurization was rapid (HTST), and $400 \mathrm{~kg}$ of cheese was produced per week.

\section{Molecular Characterization}

The strains were reactivated in Brain Heart Infusion broth (BHI, Oxoid, UK). The cell pellet was harvested by centrifugation at $12,000 \mathrm{rpm} / 2 \mathrm{~min}$. The cell pellet was used and DNA was extracted from samples using an AxyPrep Blood Genomic DNA Miniprep Kit (Axygen Scientific Inc., Union City, CA) according to the manufacturer's instructions. The genomic DNA was stored at $-20^{\circ} \mathrm{C}$ until further analysis.

Classification of isolates as negative or positive coagulase was conducted using PCR of the coa gene according to Aarestrup et al. (1995) with modifications. When confirmed as coagulase positive, a multiplex PCR was performed to identify Staphylococcus intermedius, S. aureus, and Staphylococcus hyicus (Sasaki et al., 2010). For identification of other species, amplification of the $\operatorname{sod} A$ gene as described by Silva et al. (2014) was completed. The DNA was purified using Illustra, GFX PCR DNA, and Gel Band Purification Kit (GE Healthcare, Amersham, UK) and Sanger sequencing was performed. Posterior comparison of the FASTA sequence against sequences stored in BLAST (http://blast.ncbi.nlm.nih.gov/Blast.cgi; Benson et al., 2009; Sayers et al., 2009) was completed to identify the species.

Genes encoding enterotoxin, hemolysin, exfoliative toxin, Panton-Valentine leukocidin, and toxic shock syndrome toxin were identified using oligonucleotide sequences previously described, the sequences corresponding to the genes sea, seb, sec, sed (Johnson et al., 1991), see (Mehrotra et al., 2000), seg, seh, sei (Omoe et al., 2002), sel $j$ (Nashev et al., 2004), selk (Omoe et al., 2005), sell (Cremonesi et al., 2005), selm, seln, selo

Table 1. Origin and number of Staphylococcus isolated per cheese processing plant enrolled in this study

\begin{tabular}{lcccc}
\hline & \multicolumn{3}{c}{ No. of isolates } & \\
\cline { 2 - 4 } Origin & Dairy A & Dairy B & Dairy C & Total \\
\hline Raw milk & 23 & 2 & 4 & 29 \\
Pasteurized milk & 0 & 0 & 1 & 1 \\
Food handler & 20 & 7 & 0 & 27 \\
Table & 0 & 1 & 2 & 3 \\
Floor & 0 & 1 & 0 & 1 \\
Cheese before packing & 6 & 2 & 0 & 8 \\
Cheese after packing & 15 & 8 & 0 & 2 \\
Brine & 2 & 0 & 2 & 3 \\
Milk tank & 1 & 0 & 0 & 1 \\
Packer & 1 & 0 & 0 & 1 \\
Cheese mold & 1 & 0 & & 2 \\
\hline
\end{tabular}


(Ote et al., 2011), selp, selq, ser (Omoe et al., 2005), ses, set (Ono et al., 2008), selu (Fischer et al., 2009), selv (Thomas et al., 2009), selx (Wilson et al., 2011), hla, hlb, hld, hlg, hlg-v (Jarraud et al., 2002), eta, etb (Jarraud et al., 2002), etd (Yamaguchi et al., 2002), tst (Jarraud et al., 2002), and pvl (Lina et al., 1999). Multiplex or uniplex PCR were completed as described by previously published studies with modifications, which were described in another study conducted by our research group (data not published). The antibiotic resistant genes tetK, tetL, tetM (Gómez-Sanz et al., 2010), ant(4')-Ia (van de Klundert and Vliegenthart, 1993), ermA, ermB, ermC (Gómez-Sanz et al., 2010), $m e c A$ (Moon et al., 2007), and $m e c A_{\mathrm{LGA} 251}$ (Cuny et al., 2011) were identified as previously described. The antibiotic resistance genes and virulence factor genes were tested in all isolates. All PCR performed included positive and negative controls, where the positive controls were provided by Hygiene and Dairy Laboratory, University of São Paulo.

Through molecular typing, the spa region was amplified by PCR according to the website www.ridom. com. The DNA was purified using Illustra, GFX PCR DNA, and Gel Band Purification Kit (GE Healthcare, Buckinghamshire, UK) and sequenced using the Sanger method. Repeats and spa types were identified using the databases accessed in the http://spa.ridom.de/ repeats.shtml and http://spa.ridom.de/spatypes.shtml, respectively. Multi-locus sequence type was completed as described by Enright et al. (2000). The SCCmec type (I to $\mathrm{V}$ ) for mecA-positive strains was performed according to Zhang et al. (2005) and Kondo et al. (2007).

\section{Phenotypic Characterization of Antibiotic Resistance}

Disk diffusion method was carried out according to the Clinical and Laboratory Standards Institute (2015) to identify antibiotic resistance of the isolates. The antibiotics tested were penicillin (PEN), cefoxitin (FOX), oxacillin (OXA), erythromycin (ERI), clindamycin (CLI), chloramphenicol (CHL), ciprofloxacin (CIP), tobramycin (TOB), TET, and GEN.

\section{RESULTS}

Of the total, $92.0 \%$ of the isolates were identified as coagulase positive, and $8.0 \%$ were coagulase negative. The prevalence of $S$. aureus ( $88 \%$ of the isolates) was observed (Table 2), followed by Staphylococcus epidermidis (6\%), S. hyicus (4\%), and Staphylococcus warneri $(2 \%)$.

The genes sed, see, ses, set, and selv were not detected. The seh gene was the most identified across all isolates; it was detected in $76.6 \%$ of the raw milk

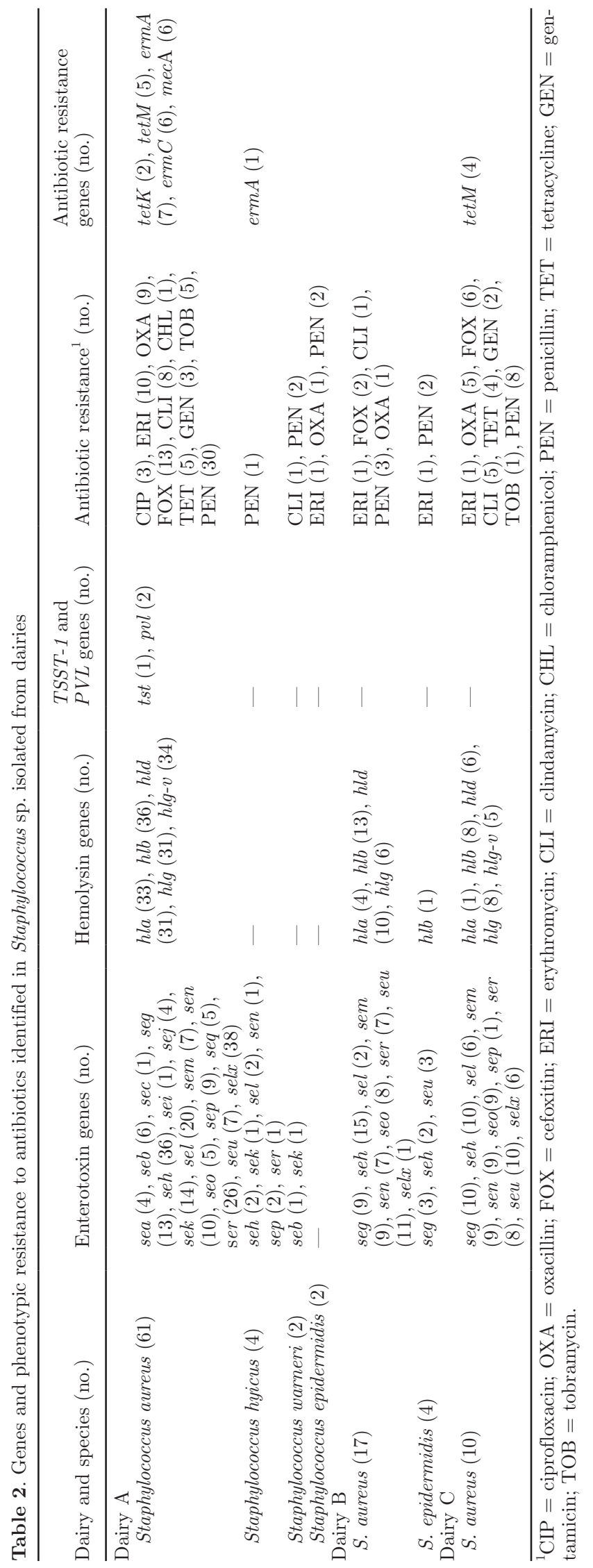

Journal of Dairy Science Vol. 100 No. 7, 2017 
samples and in $42.8 \%$ of handler, packer, table, floor, brine, milk tank, and cheese mold isolates, and in $84.3 \%$ of the cheese isolates. In total, 55 staphylococcal enterotoxin profiles were detected, 2 being the most frequent, $\quad s e g+\operatorname{seh}+\operatorname{sel} l+\operatorname{sel} m+\operatorname{sel} n+\operatorname{sel} o+\operatorname{ser}+\operatorname{seu}+\operatorname{sel} x$, and $\operatorname{seh}+\operatorname{ser}+\operatorname{sel} x$, with 7 isolates for each one. Twelve coagulase-positive staphylococci (CPS) were negative for all genes encoding enterotoxins tested. Among CNS 3 were negative for all toxin genes assessed in this study (i.e., 2 S. epidermidis and 1 S. warneri). However, 4 CNS isolates identified as $S$. epidermidis were detected as enterotoxin genes. The profiles identified were $\mathrm{seg}$, $s e g+s e h+s e l u, s e h+s e l u$, and $s e g+s e l u$, and $1 S$. warneri was also positive for enterotoxin genes, $s e b+s e l k$. For hemolysin genes, 14 hemolysin gene profiles were identified in total. The profile representing all hemolysin genes ( $h l a, h l b, h l d, h l g$, and $h l g-v)$ tested was the most prevalent (28 isolates). The most abundant hemolysin gene was $h l b(58 \%)$, next hld $(47 \%), h l g(45 \%)$, hlg-v (39\%), and hla (38\%). Exfoliative toxin genes were not found, the tst gene was detected in one isolate from raw milk ( $S$. aureus, Table 2), the same isolate was carrying enterotoxin genes (sec, seg, sei, selk, sell, selm, $s e l n$, selo, selp, selu, and $s e l x$ ) and antibiotic resistance (OXA, FOX, ERI, CLI, and PEN), whereas the $p v l$ gene was detected in 2 isolates (Table 2), one from raw milk, and another from a food handler; their profiles are shown in Table 3.

Antibiotic resistance genes were identified (Table 2); $m e c \mathrm{LGA} 251$, tet $\mathrm{L}$, ant $\left(4^{\prime}\right)-\mathrm{Ia}$, and $e r m \mathrm{~B}$ genes were not observed. The gene mecA was found in isolates from the same dairy, and the SCCmec types were described as well as the profile of these strains, which are shown in the Table 3. Using the disk-diffusion method, antibiotic resistance was observed in $52 \%$ of the isolates, and resistance to PEN was the most frequent, followed by FOX, oxacilin, CLI, ERI, TET, TOB, GEN, CIP, and CHL (Table 2). In total, 18 antibiotic resistance profiles were detected in this study; the most abundant profile was PEN (23\%) followed by OXA, FOX, ERI, CLI, and PEN (3\%). Antibiotic multiresistance was observed in $27 \%$ of the isolates and $45 \%$ of the isolates were susceptible to all antibiotics tested.

The spa types detected were t002 (1.14\%), t008 $(5.68 \%)$, t021 (1.14\%), t037 (3.41\%), t064 (6.82\%), t114 (1.14\%), t127 (22.72\%), t128 (2.27\%), t177 $(2.27 \%), \mathrm{t} 267(1.14 \%), \mathrm{t} 318(1.14 \%), \mathrm{t} 521(4.54 \%), \mathrm{t} 605$ (32.95\%), t777 (1.14\%), t922 (1.14\%), t4158 (4.54\%), t5605 (1.14\%), t6367 (2.27\%), and a new type, t14969 (3.41\%). The 3 isolates with spa type t14969 were isolated from fresh cheese samples after packing, the repeats are 15-12-16-16-02-16-02-02-25-17-17-24, and its sequence type (ST) was identified as ST30 [clonal complex (CC) 30; CC30]. Enterotoxin gene profile of these isolates (spa type 14969) was seg + seh $+\mathrm{s}$ $e \mathrm{l} m+\operatorname{sel} n+\operatorname{sel} o+\operatorname{ser}+\operatorname{sel} u$; hemolysin gene profiles were $h l d+h l g+h l g-v$ (1 isolate) and $h l d+h l g$ (2 isolates) and were sensitive to all antibiotics tested.

\section{DISCUSSION}

This study showed that the distribution of Staphylococcus species is a real concern for Brazilian dairies; consequently, it is also a concern to public health. It

Table 3. Genotypic and phenotypic profiles of methicillin-resistant Staphylococcus aureus identified

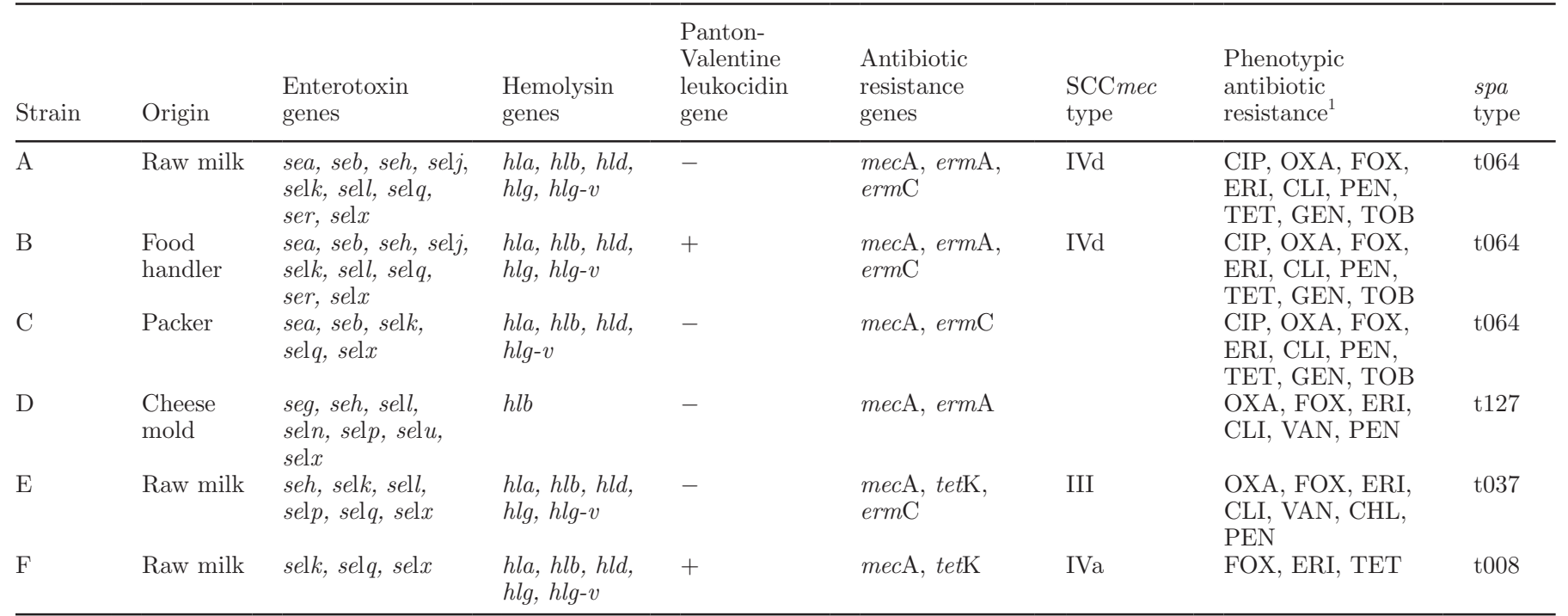

\footnotetext{
${ }^{1} \mathrm{CIP}=$ ciprofloxacin; OXA = oxacillin $; \mathrm{FOX}=$ cefoxitin $; \mathrm{ERI}=$ erythromycin; CLI = clindamycin; PEN = penicillin; TET $=$ tetracycline; GEN
} $=$ gentamicin; TOB = tobramycin; VAN = vancomycin; $\mathrm{CHL}=$ chloramphenicol. $(+)=$ gene detected; $(-)=$ gene not detected. 
is essential to control the presence of this pathogen in the food processing plant. Herein, isolates from dairies were assessed and $S$. aureus was widely identified followed by $S$. epidermidis, S. hyicus, and S. warneri, which were carrying several virulence factor genes and demonstrated antibiotic resistance. The most abundant enterotoxin gene was seh, representing SEH. Interestingly, genes encoding classical enterotoxins were either identified in low frequency or completely absent. The data highlight the importance of detecting new enterotoxins in food as well as their screening in CNS. Hemolysin genes were detected across isolates, and $p v l$ and tst were also detected. Although pvl and tst have been detected in few isolates, their importance as virulence factors should be emphasized. The research on antibiotic resistance showed the diversity on resistance among the isolates, and reported the presence of methicillin-resistant Staphylococcus aureus (MRSA), where many virulence factor genes were detected. Using molecular typing (SCCmec and spa typing), we could observe different strains, which may suggest several sources of contamination. The t605 was detected in high frequency and in samples from all dairies, indicating an endemic clone was present. Additionally, we described a new spa type, t14969, isolated from cheese.

The identification and abundance of $S$. aureus in dairy products is common (Carfora et al., 2015; Rola, et al., 2015). Minas Frescal cheese is composed of 25 to $44.9 \%$ fat and $>55 \%$ moisture, is consumed fresh (Brazil, 2004), and is a good environment for bacterial growth due to its characteristics. André et al. (2008) studied a dairy processing plant in Goiás State, Brazil, obtaining 73 S. aureus isolates with $75,66.7$, and $70.8 \%$ from handler, milk, and cheese samples, respectively, showing prevalence of this pathogen in processing plant as was observed in the present study. All species identified also have been reported in other studies involving Staphylococcus in dairies and bovine milk (André et al., 2008; Ote et al., 2011; Lange et al., 2015).

In our study $85 \%$ of isolates were potentially enterotoxigenic, carrying one or more staphylococcal enterotoxin genes. Aydin et al. (2011) observed that $62.6 \%$ of 147 isolates were enterotoxigenic and performed PCR to investigate 17 staphylococcal enterotoxin-encoding genes. The enterotoxin genes encode $\mathrm{SEH}$, followed by SEIX, and SER were predominantly identified in this study. Ote et al. (2011) reported that only $1.7 \%$ of the isolates associated with bovine mastitis carried seh. Interestingly, seh was reported as rare or absent in mastitis-associated isolates (Ote et al., 2011). However, Liu et al. (2014) described seh as the most prevalent gene among isolates from bovine mastitis, a disease that it is an important entry point for the pathogen in dairy products. In another study using isolates from food samples, seh was found in $16.3 \%$ of the isolates (Aydin et al., 2011). Therefore, our findings suggest that seh is a common gene in staphylococci and is distributed in this specific cheese production, predominantly in isolates from raw milk. The SEH represents an important staphylococcal enterotoxin because it can cause staphylococcal food poisoning, thus highlighting the importance of screening for other staphylococcal enterotoxins in food. André et al. (2008) reported that raw milk appears to be the potential source of cheese contamination. The second most identified SE gene was $s e l x$, which was recently discovered and was described as a unique core genome-encoded superantigen (Wilson et al., 2011). It was acquired by an ancestor of $S$. aureus species, and has undergone functional and genetic diversification in clones that infect humans and animals (Wilson et al., 2011), which can explain the high frequency of the sel $x$ gene. To the best of our knowledge, no report has identified sel $x$ in isolates from cheeses and samples from a food processing plant. The gene ser was widely identified ( $42 \%$ of the isolates); however, studies have demonstrated the lower frequency of this gene (e.g., $5.4 \%$ isolates from food poisoning cases; Chiang et al., 2008), 4.3\% (isolates from bovine mastitis; Liu et al., 2014), and $28.6 \%$ (isolates from milk and dairy products of different animals; Carfora et al., 2015). Both enterotoxins SEH and SER have emetic activity and staphylococcal food poisoning caused by SEH has been described (Ikeda et al., 2005; Jørgensen et al., 2005). The presence of SER has been identified in isolates from food poisoning cases (Chiang et al., 2008), which is a concern because the screening procedures commonly performed in food typically involve detection of classical enterotoxins (Lis et al., 2012). The frequency of classical enterotoxins was low or absent, and similar results have been cited in previous studies (Arcuri et al., 2010; Aydin et al., 2011; Liu et al., 2014). Moreover, cheese before and after packing contained the enterotoxin gene in 100 and $95.83 \%$ of isolates, respectively; this high prevalence of isolates from ready-to-eat food is a concern. In addition, 55 enterotoxin profiles were observed in 100 isolates enrolled in this study, showing the high distribution of enterotoxin genes (e.g., in a previous study 59 superantigenic toxin gene profiles in 229 isolates were described; Ote et al., 2011).

Regarding hemolysin genes, $63.4 \%$ of isolates carried one or more genes, and it is important to underline the significance of $h l b$ because $\beta$-hemolytic $S$. aureus has been reported as being more virulent to cattle than $\beta$-hemolytic negative strains. The $h l b$ may be an active factor in development of bovine mastitis (Larsen et al., 2002), which may indicate that the presence of the 
majority of the staphylococci in the cheese production process was caused by use of raw milk contaminated by staphylococci from mastitic milk.

Herein, exfoliative toxin encoding genes were not detected and similar results were previously cited (Aydin et al., 2011; Ote et al., 2011). The tst gene was identified only in one isolate from raw milk, which showed several enterotoxin genes and resistance to antibiotics. Similarly, another study showed that $2.8 \%$ of the isolates from bulk tank milk and Minas cheese were positive for tst (Arcuri et al., 2010). In isolates from mastitic milk, the presence of tst gene was reported to be $27.5 \%$ (Ote al., 2011). Regarding the PantonValentine leukocidin, Naimi et al. (2003) reported that the MRSA acquired or associated with the community (CA-MRSA) boasts pvl. In our study, it was observed that both isolates carrying $p v l$ were MRSA, and these are SCCmec types associated with CA-MRSA. The data showed the presence of resistant and potentially virulent strains; studies of bacterial dissemination from dairy farm to the final product could help to include prevention actions in the chain.

Antibiotic resistance genes were identified and the $m e c \mathrm{~A}$-positive isolates (6.81\% of the $S$. aureus isolates) detected were carrying different genes, and presenting different spa types. Meanwhile, Rola et al. (2015) studied isolates from raw milk and observed no positive isolate for the mecA and mecC genes. Methicillin-resistant $S$. aureus containing mec $C$ from humans and cattle were reported in the United Kingdom and Denmark (Cuny et al., 2011). In high proportions, MRSA incurs greater risk and the need for more toxic drug treatments, thus increasing costs and side effects, and ultimately driving resistance in this species, other species, or both (WHO, 2014). Methicillin-resistant $S$. aureus have evolved with increased pathogenic potential; the strains are capable of causing persistent infections in hospitalized patients and healthy individuals in the community (Chatterjee and Otto, 2013). Moreover, MRSA harbor resistance to majority of the antibiotics (Chatterjee and Otto, 2013). On SCCmec typing, the types III and IV were found, and are usually associated with hospital-associated MRSA, and CA-MRSA or livestock-associated MRSA, respectively (Deurenberg and Stobberingh, 2009; Catry et al., 2010). Currently, livestock-associated MRSA infection has been cited in several species, including bovines (Luini et al., 2015). Although MRSA have been widely used to define $S$. aureus resistant to methicillin, the Centers for Disease Control and Prevention stated that this definition not only regards methicillin resistance, but that MRSA also included common antibiotics (e.g., OXA; Chatterjee and Otto, 2013). The mecA, in general, present resistance against many $\beta$-lactam antibiotics, and SCCmec elements may contain genes for resistance to antibiotics not $\beta$-lactam (Chatterjee and Otto, 2013). Thus, the nondetection of mecA in isolates positive for antibiotic used to screen MRSA may suggest the presence of other resistance mechanisms, not classical MRSA, such as modified $S$. aureus, which possess modification of existing PEN-binding proteins (Bhutia et al., 2012). Moreover, the absence of resistance to antibiotics considered markers (e.g., OXA and $\mathrm{PEN}$ ) in mecA-positive isolate can be a result intrinsic to the method used. Oxacillin disk diffusion can fail to detected heterogeneous MRSA populations, which also motivated the use of a FOX disc test described as more efficient to methicillin resistance screening (Maalej et al., 2012).

Using the phenotypic test of antibiotic resistance, we detected resistance to PEN was the most frequent among the isolates. In addition, resistance for all antibiotics was identified as well as multiresistance. Rola et al. (2015) tested 10 antibiotics using the minimum inhibitory concentration method in isolates from milk, and detected that $43 \%$ of isolates were resistant to one or more antibiotic and also that resistance to PEN was the most frequent. André et al. (2008) did not detect resistance for CIP, GEN, vancomycin, and they observed that resistance to PEN (69.9\% of isolates) was more frequent than other antibiotics tested. The majority strains are resistant to PEN or ampicillin because of long-term use of these antibiotics in agriculture and healthcare (Moon et al., 2007).

Regarding typing, we identified several spa types across $S$. aureus from different samples. Aydin et al. (2011) reported that the high genetic diversity indicates that contamination of food products with $S$. aureus could originate from different sources (e.g., preprocessing environments, processing areas, and market place). Furthermore, the same spa type was detected in different samples (e.g., t127 was identified in isolates from handler, cheese, mold cheese, and raw milk) which may suggest cross-contamination. The type t605 was widely identified; this type t605 was identified in $37.5 \%$ of isolates from mastitic milk in Brazil (Silva et al., 2013). Another study using isolates from food handlers this type was not detected (Ho et al., 2015). However, in the present study, 10 isolates from handlers were identified with this spa type. Ho et al. (2015) indicated t127 as the most abundant among the types found in $S$. aureus from food handlers, and they reported that it was observed in persistent and transient carriers. In our study, the type t127 was the second type most detected and it had between 2 to 9 enterotoxin genes and 1 to 5 
hemolysin genes. Both t605 and t127 were previously identified as abundant in isolates from mastitic milk in the same region sampled in Brazil (Silva et al., 2013).

The new spa type t14969 was first reported in this study; it was ST30 and CC30. Contemporary S. aureus CC30 lineage is associated with infections, infections which are considered complicated (Sharma-Kuinkel et al., 2015). The lineage diverged from the phage-type $80 / 81 S$. aureus clone that was responsible for the major bacterial epidemic in the 20th century (SharmaKuinkel et al., 2015).

\section{CONCLUSIONS}

The enterotoxin genes were widely identified across isolates, the most abundant gene being seh, followed by sel $x$ and ser. Hemolysin, Panton-Valentine leukocidin, and toxic shock syndrome toxin genes were also detected among the isolates, illustrating the pathogenic potential of these. Methicillin-resistant S. aureus were identified, specifically SCCmec III, IVa, IVd, and 2 nontypeable, and carried hemolysin, enterotoxin, Panton-Valentine leukocidin, TET, and ERI genes. Using spa typing, we detected several types distributed in the isolates from different samples; however, a dominant type was identified. The majority of $S$. aureus was identified as $\mathrm{t} 605$, and this was found in all dairies. Most importantly, a new spa type was described, the spa type t14969 (ST30 and CC30) isolated from fresh cheese samples after packing. According to all findings reported in the present study, it can be suggested that antibiotic resistance and highly virulent strains from different sources can be found in a dairy processing environment in Brazil, which is a real concern for researchers, producers, and consumers. Thus, improvements are still needed in Brazilian dairies to avoid contamination by staphylococci. The findings demonstrated to Brazilian producers and regulatory agencies that prevention and control actions in dairy processing should be observed and improved to warrant food safety. Further research should be conducted to analyze spread of Staphylococcus spp. strains in dairy products and the processing environment to develop prevention programs to protect consumers and avoid the dissemination of virulent and resistant bacteria.

\section{ACKNOWLEDGMENTS}

The authors thank Coordenação de Aperfeiçoamento de Pessoal de Nível Superior (CAPES, Brasília, Brazil) for financial support and Catherine H. Higgins (Cornell University, Ithaca, NY) for her assistance.

\section{REFERENCES}

Aarestrup, F. M., C. A. Dangler, and L. M. Sordillo. 1995. Prevalence of coagulase gene polymorphism in Staphylococcus aureus isolates causing bovine mastitis. Can. J. Vet. Res. 59:124-128.

André, M. C. D. P. B., M. R. H. Campos, L. J. Borges, and A. Kipnis. 2008. Comparison of Staphylococcus aureus isolates from food handlers, raw bovine milk and Minas Frescal cheese by antibiogram and pulsed-field gel electrophoresis following SmaI digestion. Food Contr. 19:200-207.

Arcuri, E. F., F. F. Angelo, M. F. Guimarães, R. Talon, M. F. Borges, S. Leroy, G. Loiseau, C. C. Lange, N. J. Andrade, and D. Montet. 2010. Toxigenic status of Staphylococcus aureus isolated from bovine raw milk and Minas Frescal cheese in Brazil. J. Food Prot. $73: 2225-2231$

Aydin, A., M. Sudagidan, and K. Muratoglu. 2011. Prevalence of staphylococcal enterotoxins, toxin genes and genetic-relatedness of foodborne Staphylococcus aureus strains isolated in the Marmara Region of Turkey. Int. J. Food Microbiol. 148:99-106.

Benson, D. A., I. Karsch-Mizrachi, D. J. Lipman, J. Ostell, and E. W. Sayers. 2009. GenBank. Nucleic Acids Res. 37:D26-D31.

Bhutia, K. O., T. S. Singh, S. Biswas, and L. Adhikari. 2012. Evaluation of phenotypic with genotypic methods for species identification and detection of methicillin resistant in Staphylococcus aureus. Int. J. Appl. Basic Med. Res. 2:84-91.

Brazil. 2004. Ministério da Agricultura, Pecuária e Abastecimento. Instrução Normativa $\mathrm{n}^{\circ} 4$, de 1 de março de 2004. Accessed May 2016. http://extranet.agricultura.gov.br/sislegis-consulta/ consultarLegislacao.do?operacao=visualizarandid $=5974$.

Carfora, V., A. Caprioli, N. Marri, D. Sagrafoli, C. Boselli, G. Giacinti, G. Giangolini, L. Sorbara, S. Doratelli, A. Battisti, and S. Amatiste. 2015. Enterotoxin genes, enterotoxin production, and methicillin resistance in Staphylococcus aureus isolated from milk and dairy products in Central Italy. Int. Dairy J. 42:10-15.

Catry, B., E. Van Duijkeren, M. C. Pomba, C. Greko, M. A. Moreno, S. Pyörälä, M. Ruzauskas, P. Sanders, E. J. Threlfall, F. Ungemach, K. Törneke, C. Munoz-Madero, and J. Torren-Edo. 2010. Reflection paper on MRSA in food-producing and companion animals: Epidemiology and control options for human and animal health. Epidemiol. Infect. 138:626-644.

Chatterjee, S. S., and M. Otto. 2013. Improved understanding of factors driving methicillin-resistant Staphylococcus aureus epidemic waves. Clin. Epidemiol. 5:205-217.

Chiang, Y. C., W. W. Liao, C. M. Fan, W. Y. Pai, C. S. Chiou, and H. Y. Tsen. 2008. PCR detection of staphylococcal enterotoxins (SEs) N, O, P, Q, R, U, and survey of SE types in Staphylococcus aureus isolates from food-poisoning cases in Taiwan. Int. J. Food Microbiol. 121:66-73.

Clinical Laboratory Standards Institute. 2015. Performance Standards for Antimicrobial Susceptibility Testing. Twenty-fifth Informational Supplement, M100-S25. National Committee for Clinical Laboratory Standards, Wayne, PA

Cremonesi, P., M. Luzzana, M. Brasca, S. Morandi, R. Lodi, C. Vimercati, D. Agnellini, G. Caramenti, P. Moroni, and B. Castiglioni. 2005. Development of a multiplex PCR assay for the identification of Staphylococcus aureus enterotoxigenic strains isolated from milk and dairy products. Mol. Cell. Probes 19:299-305.

Cuny, C., F. Layer, B. Strommenger, and W. Witte. 2011. Rare occurrence of methicillin-resistant Staphylococcus aureus CC130 with a novel mecA homologue in humans in Germany. PLoS One 6: e24360.

Deurenberg, R. H., and E. E. Stobberingh. 2009. The molecular evolution of hospital- and community-associated methicillin-resistant Staphylococcus aureus. Curr. Mol. Med. 9:100-115.

Downes, F. P., and K. Ito. 2001. Compendium of methods for the microbiological examination of foods. 4th ed. American Public Health Association, Washington, DC.

Enright, M. C., N. P. Day, C. E. Davies, S. J. Peacock, and B. G. Spratt. 2000. Multilocus sequence typing for characterization of 
methicillin-resistant and methicillin-susceptible clones of Staphylococcus aureus. J. Clin. Microbiol. 38:1008-1015.

Fischer, A., P. Francois, S. Holtfreter, B. Broeker, and J. Schrenzel. 2009. Development and evaluation of a rapid strategy to determine enterotoxin gene content in Staphylococcus aureus. J. Microbiol. Methods 77:184-190.

Gómez-Sanz, E., C. Torres, C. Lozano, R. Fernández-Pérez, C. Aspiroz, F. Ruiz-Larrea, and M. Zarazaga. 2010. Detection, molecular characterization, and clonal diversity of methicillin-resistant Staphylococcus aureus CC398 and CC97 in Spanish slaughter pigs of different age groups. Foodborne Pathog. Dis. 7:1269-1277.

Hayakawa, Y., N. Hashimoto, K. Imaizumi, T. Kaidoh, and S. Takeuchi. 2001. Genetic analysis of exfoliative toxin A-producing Staphylococcus aureus isolated from mastitic cow's milk. Vet. Microbiol. 78:39-48.

Ho, J., M. V. Boost, and M. M. O'Donoghue. 2015. Tracking sources of Staphylococcus aureus hand contamination in food handlers by spa typing. Am. J. Infect. Control 43:759-761.

Ikeda, T., N. Tamate, K. Yamaguchi, and S. Makino. 2005. Mass outbreak of food poisoning disease caused by small amounts of staphylococcal enterotoxins A and H. Appl. Environ. Microbiol. 71:2793-2795.

Jamali, M., M. Paydar, B. Radmehr, S. Ismail, and A. Dadrasnia. 2015. Prevalence and antibiotic resistance of Staphylococcus aureus isolated from raw milk and dairy products. Food Contr. 54:384388

Jarraud, S., C. Mougel, J. Thioulouse, G. Lina, H. Meugnier, F. Forey, X. Nesme, J. Etienne, and F. Vandenesh. 2002. Relationships between Staphylococcus aureus genetic background, virulence factors, agr groups (alleles), and human disease. Infect. Immun. 70:631-641.

Jean-Baptiste, N., D. Benjamin Jr., M. Cohen-Wolkowiez, V. G. Fowler Jr., M. Laughon, R. H. Clark, and P. B. Smith. 2011. Coagulase-negative Staphylococcal infections in the neonatal intensive care unit. Infect. Control Hosp. Epidemiol. 32:679-686.

Johnson, W. M., S. D. Tyler, E. P. Ewan, F. E. Ashton, D. R. Pollard, and K. R. Rozee. 1991. Detection of genes for enterotoxins, exfoliative toxins, and toxic shock syndrome toxin 1 in Staphylococcus aureus by the polymerase chain reaction. J. Clin. Microbiol. 29:426-430.

Jorgensen, H. J., T. Mathisen, A. Lovseth, K. Omoe, K. S. Qvale, and S. Loncarevic. 2005. An outbreak of Staphylococcus food poisoning cause by enterotoxin $\mathrm{H}$ in mashed potato made with raw milk. FEMS Microbiol. Lett. 252:267-272.

Kondo, Y., T. Ito, X. X. Ma, S. Watanabe, B. N. Kreiswirth, J. Etienne, and K. Hiramatsu. 2007. Combination of multiplex PCRs for Staphylococcal Cassette Chromosome mec type assignment: Rapid identification system for mec, $c c r$, and major differences in junkyard regions. Antimicrob. Agents Chemother. 51:264-274.

Lange, C. C., M. A. V. P. Brito, D. R. L. Reis, M. A. Machado, A. S. Guimarães, A. L. Azevedo, É. B. Salles, M. C. Alvim, F. S. Silva, and I. R. Meurer. 2015. Species-level identification of staphylococci isolated from bovine mastitis in Brazil using partial 16S rRNA sequencing. Vet. Microbiol. 176:382-388.

Langsrud, S. 2009. Biofilm formation by Gram-positive bacteria including Staphylococcus aureus, Mycobacterium avium and Enterococcus spp. in food processing environments. P. M. Fratamico, B.A. Annous, and N. W. Guenther, ed. Biofilms in the Food and Beverage Industries. Woodhead Publishing Oxford, UK.

Larsen, H. D., F. M. Aarestrup, and N. E. Jensen. 2002. Geographical variation in the presence of genes encoding superantigenic exotoxins and beta-hemolysin among Staphylococcus aureus isolated from bovine mastitis in Europe and USA. Vet. Microbiol. 85:61-67.

Lina, G., Y. Piémont, F. Godail-Gamot, M. Bes, M. O. Peter, V. Gauduchon, F. Vandenesch, and J. Etienne. 1999. Involvement of Panton-Valentine leukocidin-producing Staphylococcus aureus in primary skin infections and pneumonia. Clin. Infect. Dis. 29:1128 1132.

Lis, E., M. Podkowik, J. Schubert, K. Bystron, T. Stefaniak, and J. Bania. 2012. Production of staphylococcal enterotoxin R by Staphylococcus aureus strains. Foodborne Pathog. Dis. 9:762-766.
Liu, Y., W. Chen, T. Ali, R. Alkasir, J. Yin, G. Liu, and B. Han. 2014 Staphylococcal enterotoxin $\mathrm{H}$ induced apoptosis of bovine mammary epithelial cells in vitro. Toxins (Basel) 6:3552-3567.

Luini, M., P. Cremonesi, G. Magro, V. Bianchini, G. Minozzi, B. Castiglioni, and R. Piccinini. 2015. Methicillin-resistant Staphylococcus aureus (MRSA) is associated with low within-herd prevalence of intra-mammary infections in dairy cows: Genotyping of isolates. Vet. Microbiol. 178:270-274.

Maalej, S. M., F. M. Rhimi, M. Fines, B. Mnif, R. Leclercq, and A Hammami. 2012. Analysis of borderline oxacillin-resistant Staphylococcus aureus (BORSA) strains isolated in Tunisia. J. Clin. Microbiol. 50:3345-3348.

Mehrotra, M., G. Wang, and W. M. Johnson. 2000. Multiplex PCR for detection of genes for Staphylococcus aureus enterotoxins, exfoliative toxins, toxic shock syndrome toxin 1 , and methicillin resistance. J. Clin. Microbiol. 38:1032-1035.

Ministry of Health. 2016. Surtos de Doenças Transmitidas por Alimentos no Brasil. Accessed Jan. 29, 2017. http://u.saude.gov.br/ images/pdf/2016/junho/08/Apresenta-o-Surtos-DTA-2016.pdf.

Moon, J. S., A. R. Lee, H. M. Kang, S. E. Lee, M. N. Kim, Y. H. Paik, Y. H. Park, Y. S. Joo, and C. H. Koo. 2007. Phenotypic and genetic antibiogram of methicillin-resistant staphylococci isolated from bovine mastitis in Korea. J. Dairy Sci. 90:1176-1185.

Naimi, T. S., K. H. Ledell, K. Como-Sabetti, S. M. Borchardt, D. J. Boxrud, J. Etienne, F. Vandenesch, S. Fridkin, C. O'Boyle, R. N. Danila, and R. Lynfield. 2003. Comparison of community- and health care-associated methicillin-resistant Staphylococcus aureus infection. JAMA 290:2976-2984.

Nashev, D., K. Toshkova, S. Isrina, S. Salaisa, A. A. Hassan, C. Lämmler, and M. Aszhöck. 2004. Distribution of virulence genes of Staphylococcus aureus isolated from stable nasal carriers. FEMS Microbiol. Lett. 233:45-52.

Omoe, K., D. L. Hu, H. Takahashi-Omoe, A. Nakane, and K. Shinagawa. 2005. Comprehensive analysis of classical and newly described staphylococcal superantigenic toxin genes in Staphylococcus aureus isolates. FEMS Microbiol. Lett. 246:191-198.

Omoe, K., M. Ishikama, Y. Shimoda, D. L. Hu, S. Ueda, and K. Shinagawa. 2002. Detection of seg, seh and sei genes in Staphylococcus aureus isolates and determination of the enterotoxin productivities of $S$. aureus isolate harboring seg, seh or sei genes. J. Clin. Microbiol. 40:857-862.

Ono, H. K., K. Omoe, K. Imanishi, Y. Iwakabe, D. L. Hu, H. Kato, N. Saito, T. Uchiyama, and K. Shinagawa. 2008. Identification and characterization of two novel staphylococcal enterotoxins, types $\mathrm{S}$ and T. Infect. Immun. 76:4999-5005.

Ote, I., B. Taminiau, J. N. Duprez, I. Dizier, and J. G. Mainil. 2011. Genotypic characterization by polymerase chain reaction of Staphylococcus aureus isolates associated with bovine mastitis. Vet. Microbiol. 153:285-292.

Podkowik, M., J. Y. Park, K. S. Seo, J. Bystroń, and J. Bania. 2013. Enterotoxigenic potential of coagulase-negative staphylococci. Int J. Food Microbiol. 163:34-40.

Rola, J. G., W. Korpysa-Dzirba, A. Czubkowska, and J. Osek. 2015. Prevalence of enterotoxin genes and antibiotic resistance of coagulase-positive staphylococci recovered from raw cow milk. J. Dairy Sci. 98:4273-4278.

Sasaki, T., S. Tsubakishita, Y. Tanaka, A. Sakusabe, M. Ohtsuka, S. Hirotaki, T. Kawakami, T. Fukata, and K. Hiramatsu. 2010 Multiplex-PCR method species identification of coagulase-positive staphylococci. J. Clin. Microbiol. 48:765-769.

Sayers, E. W., T. Barrett, D. A. Benson, S. H. Bryant, K. Canese, V. Chetvernin, D. M. Church, M. DiCuccio, R. Edgar, S. Federhen, M. Feolo, L. Y. Geer, W. Helmberg, Y. Kapustin, D. Landsman, D. J. Lipman, T. L. Madden, D. R. Maglott, V. Miller, I. Mizrachi, J. Ostell, K. D. Pruitt, G. D. Schuler, E. Sequeira, S. T. Sherry, M. Shumway, K. Sirotkin, A. Souvorov, G. Starchenko, T. A. Tatusova, L. Wagner, E. Yaschenko, and J. Ye. 2009. Database resources of the National Center for Biotechnology Information. Nucleic Acids Res. 37:D5-D15

Shaheen, M., H. A. Tantary, and S. U. Nabi. 2016. A treatise on bovine mastitis: Disease and disease economics, etiological basis, risk fac- 
tors, impact on human health, therapeutic management, prevention and control strategy. J. Adv. Dairy Res. 4:1-10.

Sharma-Kuinkel, B. K., E. F. Mongodin, J. R. Myers, K. L. Vore, G. S. Canfield, C. M. Fraser, T. H. Rude, V. G. Fowler Jr., and S. R. Gill. 2015. Potential influence of Staphylococcus aureus Clonal Complex 30 genotype and transcriptome on hematogenous infections. Open Forum Infect. Dis. 2:ofv093.

Silva, G. O. 2013a. Genotypic and phenotypic study of potentially enterotoxigenic coagulase positive staphylococci isolated from production lines of Minas fresh cheese in São Paulo. Accessed May 2016. http://www.teses.usp.br/teses/disponiveis/11/11141/tde04022014-085410/pt-br.php.

Silva, N. C. C., F. F. Guimarães, M. P. Manzi, P. E. Budri, E. GómezSanz, D. Benito, H. Langoni, V. L. Rall, and C. Torres. 2013b. Molecular characterization and clonal diversity of methicillin susceptible Staphylococcus aureus in milk of cows with mastitis in Brazil. J. Dairy Sci. 96:6856-6862.

Silva, N. C. C., F. F. Guimarães, M. P. Manzi, E. Gómez-Sanz, P. Gómez, J. P. Araújo-Júnior, H. Langoni, V. L. Rall, and C. Torres. 2014. Characterization of methicillin-resistant coagulase-negative staphylococci in milk from cows with mastitis in Brazil. Antonie van Leeuwenhoek 106:227-233.

Thomas, D., O. Dauwalder, V. Brun, C. Badiou, T. Ferry, J. Etienne, F. Vandenesch, and G. Lina. 2009. Staphylococcus aureus superantigens elicit redundant and extensive human Vbeta patterns. Infect. Immun. 77:2043-2050.

van de Klundert, J. A. M., and J. S. Vliegenthart. 1993. PCR detection of genes for aminoglycoside-modifying enzymes. D. H.
Persing, T. F. Smith, F. C. Tenover, and T. J. White, ed. Pages 547-552 in Diagnostic Molecular Microbiology. American Society for Microbiology, Washington, DC.

WHO. 2014. Antibiotic resistance: Global report of surveillance. Accessed May 2016. http://apps.who.int/iris/bitstre am/10665/112642/1/9789241564748_eng.pdf?ua=1.

Wilson, G. J., K. S. Seo, R. A. Cartwright, T. Connelley, O. N. Chuang-Smith, J. A. Merriman, C. M. Guinane, J. Y. Park, G. A Bohach, P. M. Schlievert, W. I. Morrison, and J. R. Fitzgerald. 2011. A novel core genome-encoded superantigen contributes to lethality of community-associated MRSA necrotizing pneumonia. PLoS Pathog. 7:e1002271.

Xing, X., Y. Zhang, Q. Wu, X. Wang, W. Ge, and C. Wu. 2016 Prevalence and characterization of Staphylococcus aureus isolated from goat milk powder processing plants. Food Contr. 59:644-650.

Yamaguchi, T., K. Nishifuji, M. Sasaki, Y. Fudaba, M. Aepfelbacher, T. Takata, M. Ohara, H. Komatsuzawa, M. Amagau, and M. Sugai. 2002. Identification of the Staphylococcus aureus etd pathogenicity island which encodes a novel exfoliative toxin, ETD, and EDIN-B. Infect. Immun. 70:5835-5845.

Zhang, K., J. A. McClure, S. Elsayed, T. Louie, and J. M. Conly. 2005. Novel multiplex PCR assay for characterization and concomitant subtyping of staphylococcal cassette chromosome mec types I to V in methicillin-resistant Staphylococcus aureus. J. Clin. Microbiol. 43:5026-5033. 